\title{
Betonarme Binalarda Bölme Duvar Etkilerinin Tam Ölçekli Deneylerle Araştırılması
}

\author{
Fuat ARAS 1
}

Öz

Bu çalışmada betonarme yapılarda bulunan bölme tuğla duvarların bina dinamik özelliklerine olan etkisi deneysel çalışmalarla belirlenmiştir. Çalışmada, 1980'li yıllarda inşa edilmiş altı katlı betonarme bir bina deney numunesi olarak kullanılmıştır. Çalışılan binanın dinamik özellikleri çevresel titreşim analizleri ile belirlenmiştir. Daha sonra binanın zemin katında bulunan tuğla ve çimento harcıyla örülmüş bölme duvarlar doldurdukları çerçevelerden ayrılarak etkisizleştirilmiştir. Tekrarlanan çevresel titreşim analizleriyle, binanın zemin katında bölme duvarları olmaması durumunda dinamik özellikler belirlenmiştir. Çalışılan binanın iki hali için belirlenen dinamik özelliklerin karşılaştırılmasıyla, bölme duvarların yapı dinamik davranışlarına olan katkıları belirlenmiştir.

Anahtar Kelimeler: Bölme duvarlar, betonarme binalar; dinamik davranış, deneysel modal analiz, düzensizlikler.

\section{ABSTRACT \\ Investigation of Effects of Infill Walls in Reinforced Concrete Buildings with Full- Scaled Experiments}

In this study, the effects of partition walls into dynamic behavior of reinforced concrete building are investigated with experimental researches. A six-story reinforced concrete building, constructed in 1980s, is used as a test specimen. The dynamic characteristics of the studied building are determined by ambient vibration survey. Later on the partition walls, composed of bricks and cement mortar, are set ineffective by separating them from the frames they fill. The repeated ambient vibration survey gives the dynamic characteristics of the building which does not have partition walls on its ground floor. The comparison of the determined dynamic characteristics for two forms of the same building revealed the contribution of partition walls into the dynamic properties of the building.

Keywords: Partition walls, reinforced concrete buildings; dynamic behavior, experimental modal analysis, irregularities.

\footnotetext{
Not: Bu yazı

- Yayın Kurulu'na 21.04.2017 günü ulaşmıştır. 16.11.2017 günü yayımlanmak üzere kabul edilmiştir.

- 30 Kasım 2018 gününe kadar tartı̧̧maya açıktır.
}

- DOI: $10.18400 /$ tekderg. 317218

1 İstanbul Medeniyet Üniversitesi, İnşaat Mühendisliği Bölümü, İstanbul - fuataras@hotmail.com 


\section{GíRIŞ}

Betonarme binalarda bulunan duvarlar, binaların iç bölümlerinin ayrılmasında ve mekânların dış etkilerden korunmasında sıklıkla kullanılmaktadır. Genel olarak yapısal olmayan elemanlar olarak sınıflandırılan bölme duvarların yapıya kattıkları dayanım ve rijitlik etkisi tasarım aşamasında dikkate alınmamasına rağmen, yapının genel davranışını etkiledikleri bilinmektedir.

Son zamanlarda bölme duvarların yapısal davranışa olan etkilerinin ortaya çıkarılması ve tasarım aşamasında göz önüne gerçekçi olarak alınması için yapılmış birçok deneysel ve sayısal araştırmalar mevcuttur. Fiore ve diğ. literatürde bulunan çerçeve üzerinde gerçekleştirilen deneysel çalışmalarını sonlu elemanlar yöntemi ile doğrulamaya çalışmıştır [1]. Bir başka çalışmada, Uva ve diğ. Güney İtalya' da bulunan bölme duvarlı betonarme bir bina için bölme duvarların etkisini doğrusal olmayan sayısal analizlerle araştırmışlardır. Mevcut yapının bölme duvarlarından alınan deney numuneleri laboratuvarda test edilmiş ve sonuçlar sayısal modellerde kullanılmıştır. Bölme duvarların değişik mukavemet değerlerine göre yapı dinamik davranışında ve performansında görülen değişimler sunulmuştur [2]. Köse ise sonlu elemanlar yöntemi ile modellenmiş 189 adet bina için yapılan sayısal analizler sonunda bölme duvarların yapı periyoduna olan etkisini araştırmıştır. Yazar bölme duvarların yapıların periyotlarını \% 5 - \% 10 mertebesinde düşürdüğü sonucuna varmıştır [3]. Ayrıca, bölme duvarların yapı dayanım ve sünekliğine olan katkısı sarsma tablası üzerinde yapılanan deneylerle de araştırılmıştır [4 - 6]. Dolgu duvarların betonarme yapıların dinamik davranışına olan katkısını araştıran çalışmaların en önemlilerinden birisi Türkiye'de yürütülmüştür. İzmir Teknoloji Enstitüsü’nde bir Yüksek Lisans Tezi olarak tamamlanan çalışmada, dört adet 1/5 oranında küçültülmüş dört katlı ve tek açıklıklı deney numuneleri üzerinde bölme duvarların yapı dinamik özelliklerine olan etkisi incelenmiştir. Gerçekleştirilen dinamik ve statik testler sonucunda yığma duvarların yapı dinamik özelliklerini değiştirmesi yanında, yapı rijitliği, yapı dayanımı ve yapı sönüm oranına yaptığı katkının altı çizilmiştir [7].

Tüm bu çalışmalar bölme duvarların betonarme yapıların genel davranışına olan etkileri için önemli bilgiler vermesine karşı, sayısal yöntemler ve laboratuvarda ölçeklendirilerek üretilmiş deney numuneleri üzerinde gerçekleştirilmeleri nedeniyle mertebe olarak tahmin edilmesi güç olan bir hata içermektedirler. Öyle ki, sayısal analizlere dayalı çalışmalar modelleme teknikleri, geometrik ölçümler, sınır koşulları ve malzeme özellikleri gibi birçok parametrede idealleştirme, genelleme ve varsayımlara dayalıdır. Laboratuvar şartlarında yapılan çalışmalar ise üretilen numunelerdeki ölçeklendirme, gerçek malzeme özeliklerinin ve sınır koşullarının yakalanması ve doğal yükleme koşullarının elde edilmesindeki zorluklar nedeniyle sorguya her zaman açıktır. Ayrıca, betonun zamana ve kullanım yüklerine bağlı olan davranışının laboratuvar şartlarında hazırlanan numunelerde göz önüne alınması hiç de kolay değildir.

Sunulan bu çalışma gerçek bir bina üzerinde yürütülmüştür. Çalışma kapsamında, 1980'li yıllarda inşa edilmiş altı katlı betonarme bir binanın dinamik özellikleri çevresel titreşim analizleriyle belirlenmiştir. Daha sonra binanın zemin katında bulunan bölme duvarları kırılarak etkisizleştirilmiştir. Çevresel titreşim analizleri tekrarlanarak zemin katında bölme duvarları olmayan yapının dinamik özellikleri elde edilmiştir. Elde edilen dinamik özelliklerin doğrudan karşılaştırılması binanın zemin katında bulunan bölme duvarların yapının dinamik özelliklerine olan katkısını tam olarak ortaya çıkarmıştır. Binanın ilk hali 
yapım yılından 30 yıl sonra test edilmiştir ve bu süre içinde bina tümüyle konut olarak kullanılmıştır. Bu binanın çalışma kapsamında bir deney numunesi olarak kullanılması, sonuçların zamana bağlı etkileri de içeren gerçekçi bir çalışma olması açısından önemlidir.

Yapılardan elde edilen titreşim kayıtları birçok mühendislik probleminin çözümünde kullanılmaktadır. Makine parçalarının titreşim analizleri, uçaklardaki titreşim problemlerinin belirlenmesi, yapı dinamik karakteristiklerinin belirlenmesi titreşim analizlerinin yaygın kullanıldığı alanlardan bazılarıdır [8, 9]. Yapılar üzerinde titreşimlerin ölçülmesi ve ölçümlerden yapı dinamik parametrelerinin belirlenmesi deneysel modal analiz veya operasyonel modal analiz yöntemleri olarak da bilinmektedir. Çevresel titreşim analizlerinin gerçek betonarme yapılarda uygulanması ve yapı dinamik özelliklerinin çıkarıldığ çalışmalar da mevcuttur. Michel ve diğ. Fransa'da bulunan 54 adet betonarme binada çevresel titreşim analizi yapmış ve elde edilen frekans değerlerini kendi yönetmeliklerindeki formüllerle karşılaştırmışlardır [10]. Yönetmeliklerde bulunan ampirik periyot formüllerini irdeleyen başka bir çalışma da Türkiye'de yapılmıştır. Yürütülen deneysel çalışmada 12 katlı betonarme bir binanın inşası sırasında binanın duvarsız, duvarlı ve sıvalı durumları için çevresel titreşim analizleri uygulanmış ve belirlenen periyotlar karşılaştırılmıştır [11]. Çalışma sonucuna göre, yapıya uygulanan sıvanın duvarlı yapıda yol açtığı periyot düşüşünün, duvarların duvarsız yapıda meydana getirdiği periyot düşüşünden yüksek olması ilk önce şaşırtıcı olmakla beraber duvarlı ve sıvasız yapıda duvarların yanal rijitliğe katkı yapmaması ve sıvanın yapı elemanları ve duvar arasında bağ oluşturması ile açıklanabilir. Ayrıca yapının duvarlı hali için belirlenen dinamik özelliklerin, duvar inşasından hemen sonra gerçekleştirilmiş olması sonuçların zaman bağlı deformasyon etkilerini içermediğini göstermektedir. Çevresel titreşim analizlerinin betonarme yapılara uygulandığı bir başka çalışmada ise titreşim analizlerini güçlendirme yapılacak bir binanın güçlendirmeden önceki ve sonraki durumları için uygulamıştır. Ayrıca perde eklemesi için yıkılan bölme duvarların etkisi incelenmiş ve bu bölme duvarların yıkılmasının yapı periyodunu \%11 civarında yükselttiği belirlenmiştir [12].

Literatürde bölme duvarların betonarme yapıların dinamik davranışına ve performansına yönelik yürütülmüş başka sayısal ve deneysel çalışmalar da vardır. Literatürde bulunan deneysel çalışmalar, sayısal analizlere göre daha güvenilir olmakla beraber, ölçekleme etkileri, numune hazırlama yöntemi, numune malzemesi ve detayları ve yükleme etkileri nedeni ile birçok belirsizliği de barındırmaktadır. Ayrıca zamana bağlı deformasyonlar yığma duvar etkisini araştıran bir deneysel projede üretilecek numunelerin yıllarca yük altında bekletilmesini gerektirmektedir. $\mathrm{Bu}$ nedenlerden dolayı sunulan bu çalışma sonuçları bakımından kesin ve önemli bilgiler verecektir.

\section{2. ÇALIŞMANIN YÜRÜTÜLDÜĞÜ BİNA}

Bu çalışma kapsamında deney numunesi olarak kullanılan bina İstanbul ili Üsküdar ilçesi sınırlarında bulunmaktadır ve Şekil 1'de gösterilmiştir. Bina 1980'li yıllarda 1975 tarihli deprem yönetmeliğine [13] göre inşa edilmiş, altı katlı, zemin ve normal katlarında ikişer bağımsız bölüm ve bodrum katında bir daire ve teknik oda olan bir yapıdır. Bodrum katının etrafında betonarme perde yoktur. Halk arasında çift daire olarak anılan bu bina tipi Türkiye'de sıklıkla projelendirilip inşa edilen bir bina örneğidir. 
Binanın taşıyıcı sistemi kolon, kiriş ve kirişli döşeme sisteminden oluşmaktadır. Temel sistemi sürekli temeldir. Kolon ve kiriş boyutları katlar arasında değişmemektedir. Şekil 2 yapının taşıyıcı sistem detayını göstermektedir. Ayrıca bu çalışmada önemli olduğundan dolayı duvar yerleşimleri de detaylı olarak Şekil 3'de gösterilmiştir.

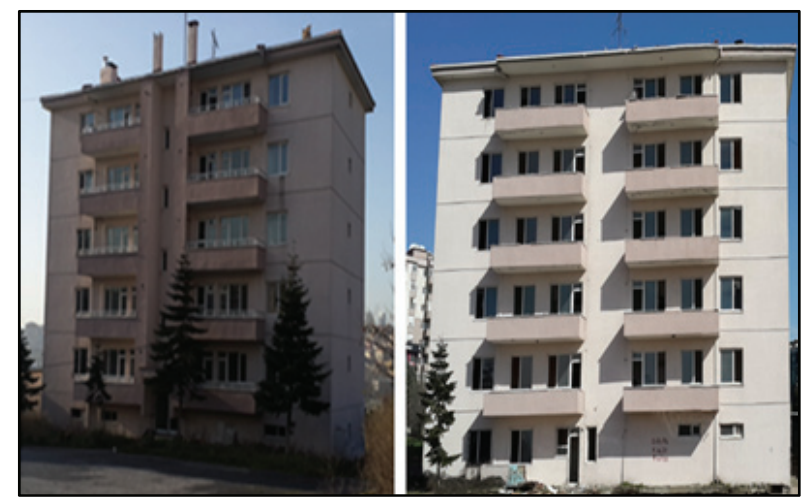

Şekil 1. Çalışmanın yürütüldüğ̈̈ bina

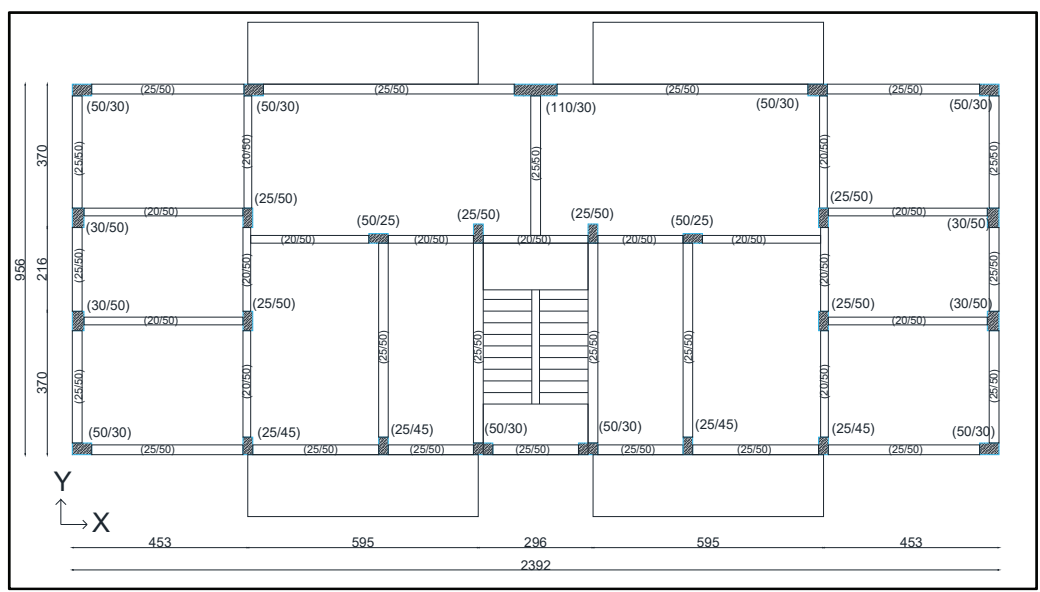

Şekil 2. Binanın belirlenen taşıyıcı sistemi



Şekil 3. Bina bodrum, zemin ve normal katları duvar yerleşimleri 


\section{BİNANIN MEVCUT HALİ İÇIN ÇEVRESEL TITREŞIM ANALIZİ}

Deneysel modal analiz yöntemiyle yapıların dinamik özelliklerinin belirlenmesi için çalışılan yapının serbestlik derecesi kadar ölçümün alınması gerekmektedir. Betonarme binaların en bilinen özelliklerinden birisi olan ve döşemeler tarafından sağlanan rijit kat seviyeleri sayesinde binadan alınması gereken ölçüm sayısını azalmaktadır. Betonarme yapılarda, bina kat seviyeleri bir bütün olarak hareket ettiğinden her bir kat için birbirine dik iki doğrultunun birinde iki, diğerinde ise bir olmak üzere toplam üç ölçüm binanın ötelenme ve burulma modlarının belirlenmesi için yeterlidir. Burulma modunun genel olarak beklenmediği düzenli binalarda her kattan alınan iki eksenli ölçümlerle de binanın ötelenme modları tespit edilebilir.

Yürütülen bu çalışmada, Kinemetrics marka 3 adet, 3 eksenli TSA-SMA model ivmeölçer kullanılmıştır. İvmeölçerlerin iki yatay doğrultusu binanın boyuna (X) ve enine (Y) doğrultusu ile eşleştirilmiş ve tüm çalışma boyunca aynı yapılandırma kullanılmıştır. Altı katlı binanın dinamik özelliklerinin baskın frekanslar ve mod şekilleri olarak üç adet ivmeölçerle tek ölçümle belirlenmesi mümkün değildir. Çünkü sahip olunan üç adet ivmeölçer ile binada üç noktanın $\mathrm{X}$ ve $\mathrm{Y}$ yönlerindeki modal yer değiştirmelerinin elde edilmesine yönelik kayıt alınabilir ve binanın baskın frekansları ve üç noktanın $\mathrm{X}$ ve $\mathrm{Y}$ yönlerindeki modal yer değiştirmeleri elde edilebilir. Oysaki binanın ötelenme modunun belirlenmesi için bina yüksekliğince her kattan ölçüm alınması gerekmektedir. Ayrıca burulma modunun her katta belirlenmesi için her katta en az iki adet ölçüme gerek vardır. Sahip olunan ivmeölçer sayısının ölçüm alınması gereken nokta sayısından az olduğu durumlarda birden fazla ölçüm seti alınması ve ivmeölçerlerden birisinin referans ivmeölçeri olarak her ölçüm setinde sabit bir yerde tutulması, diğer ivmeölçerlerin farklı yerlerden alınacak ölçümler için kullanılması yöntemi uygulanabilir. Her ölçüm setinde, eşzamanlı olarak üç noktadan alınan titreşim kayıtları işlenerek üç noktanın belli frekansta binanın mod şeklindeki modal yer değiştirme değeri elde edilir. Sonraki ölçüm setinde, ivmeölçerlerden birisi yer değiştirmez, diğer ikisi yer değiştirir. Böylelikle ikinci ölçümde yine üç noktanın belli frekanstaki modal yer değiştirmeleri elde edilir. İki ölçüm seti, yer değiştirmeyen ivmeölçerin modal yer değiştirmesi eşitlenerek birleştirilebilir. Böylelikle ölçüm seti sayısı artırılarak yüksek serbestlik dereceli sistemlerin dinamik özellikleri az sayıda ivmeölçer kullanilarak elde edilebilir [14, 15].

Çalışmanın yürütüldüğü binanın çatı seviyesinden, erişimin tehlikeli olması nedeniyle, ölçüm alınmamıştır. Bu nedenle bina ötelenme modları her iki yönde temel ve kat seviyelerinden alınan ölçümlerle belirlenmiştir. Ayrıca binanın en üst katında burulma modunun belirlenmesine yönelik üç ivmeölçerle tek ölçüm yapılmıştır. Şekil 4 çalışma kapsamında ivmeölçerlerle kayıt alınmasını ve bu kayıtlardan birisinin $X, Y$ ve $Z$ (düşey) doğrultularındaki değişimlerini göstermektedir. Çalışma kapsamında her ölçüm için kayıt süresi 20 dakika olarak belirlenmiştir ve ölçümler saniyede 200 kayıt alınarak gerçekleştirilmiştir. Brincker kuralına göre kayıt süresinin yapı periyodunun en az 1000 katı olması doğru bir sistem tanımlama için gereklidir [16]. Ayrıca binadan saniyede 200 kayıt alınması, baskın frekansların doğru olarak ortaya çıkarılması açısından yeterli hassasiyeti barındırmaktadır. Bu nedenlerle, kayıt süresi ve veri kayıt frekansı, çalışılan binada doğru bir sistem tanımlama için gerekli özelliklere sahiptir.

Yapılardan alınan ölçümlerden yapı dinamik özeliklerinin belirlenmesi için geliştirilmiş farklı sistem tanımlama yöntemleri mevcuttur. Sinyallerin zaman ortamından, FFT (Fast 
Fourier Transform) dönüşümleriyle frekans ortamına geçirilmeleri binanın baskın frekanslarının belirlenmesi için yeterlidir. Ancak, mod şekillerinin belirlenmesi için ilave analizlerin yapılması gereklidir. Bu noktada sistem tanımlama ile ilgili birçok yöntem vardır ve bu yöntemlerle ilgili detaylı bilgi bu çalışmada kullanılan Frekans Ortamında Ayrışım, FOA (Frequency Domain Decomposition, FDD) dışında verilmeyecektir. Bayraktar ve diğ. [8] tarafından da açıklandığı üzere, bilinmeyen etki ve ölçülen tepki fonksiyonları arasındaki bağıntı,

$\left[G_{y y}(w)\right]=[H(w)]^{*}\left[G_{x x}(w)\right][H(w)]^{T}$

şeklinde tanımlanmaktadır. Burada $\left[G_{x x}(w)\right]$ ve $\left[G_{y y}(w)\right]$ etki ve tepki sinyallerine ait güç spektral yoğunluk fonksiyonlarını, $[H(w)]$ ise frekans davranış fonksiyonunu göstermektedir. Bu ifadedeki * ve T fonksiyonların eşlenik ve transpozesini göstermektedir. Bu bağıntıda etkinin beyaz gürültü olduğu varsayılarak etki sinyaline ait spektral yoğunluk fonksiyonu sabit alınmıştır. Tepki sinyaline ait güç spektral yoğunluk fonksiyonu, tekil değer ayrışımı gerçekleştirilerek ayrık değerler olarak,

$G_{y y}\left(j w_{i}\right)=U_{i} S_{i} U_{i}^{H}$

şeklinde verilmektedir. Burada; $U_{i}, u_{i j}$ tekil vektörlerinden (mod vektörlerinden) oluşan birim matrisi, $\mathrm{S}_{\mathrm{i}}, \mathrm{S}_{\mathrm{ij}}$ tekil değerlerden (öz değerlerden) oluşan diyagonal matrisi göstermektedir. $\mathrm{Bu}$ yöntemde yapıyı titreştirmek amacıyla uygulanan kuvvetin genliği ve zamanla değişimi tam olarak bilinemediğinden dolayı, ölçümler yapının ölçüm yapılan frekans aralığında tahrik edilmesini temin edebilecek kadar uzun süreli alınmalıdır. Ölçümlerde sadece yapıya ait tepkiler zaman ortamında belirli noktalardan ölçülmekte ve farklı yöntemler kullanılarak yapı dinamik parametreleri elde edilmektedir $[8,10]$.

Çalışma kapsamında Matlab programının SVD (Singular Value Decomposition) ve CPSD (Cross Power Spectral Density) fonksiyonlarından yararlanılmıştır [17]. Eş zamanlı dinamik ölçümler üç adet ivmeölçerle gerçekleştirildiğinden üzerinde çalış1lan ve daha önce açıklanan matrisler $3 x 3$ boyutundadır. Analizler X ve Y yönleri için ayrı ayrı yürütülmüştür. Şekil 5 ve Şekil 6 binada, beşinci kat B köşesi referans noktası olarak alındığında, ivmeölçerlerin 5. 2. ve 1. katlarda ve 5. 4. ve 3. katlarda olmaları ölçüm setlerinde, elde edilen CPSD matrislerinin tekil değerlerini $\mathrm{X}$ ve $\mathrm{Y}$ yönleri için göstermektedirler.

Frequency domain decomposition methodunun binanın birinci modunu Y tönünde 4,01 Hz'lik frekansla, ikinci modunu $\mathrm{X}$ yönünde $4,59 \mathrm{~Hz}$ frekansla verdiği açıkça görülmektedir. Ayrıca her iki yönde de ikinci baskın frekans olarak 5,42 Hz'lik değer dikkat çekmektedir. Bu ortak tepe noktası, binanın her iki doğrultuda da modal yer değiştirmeye sahip olduğunun göstergesidir. $\mathrm{Bu}$ ise, açıkça bu frekansta, binanın burulma moduna sahip olduğunun göstergesidir. Bir başka değişle binanın üçüncü modu 5,42 Hz'lik frekansla burulma modu olarak tespit edilmiştir. Bu yöntemle elde edilen mod şekilleri B köşesi boyunca Şekil 7'de gösterilmiştir. Mod şekillerinin tepe noktası deplasmanı bir olacak şekilde ölçeklendirilmiştir. Binanın diğer modları $10 \mathrm{~Hz}$ 'in üzerindeki frekans değerlerinde tespit edilebilir. Ancak çalışılan yapının genel özellikleri nedeniyle bu modlar yapının davranışını belirlemede çok önemli değildir. 


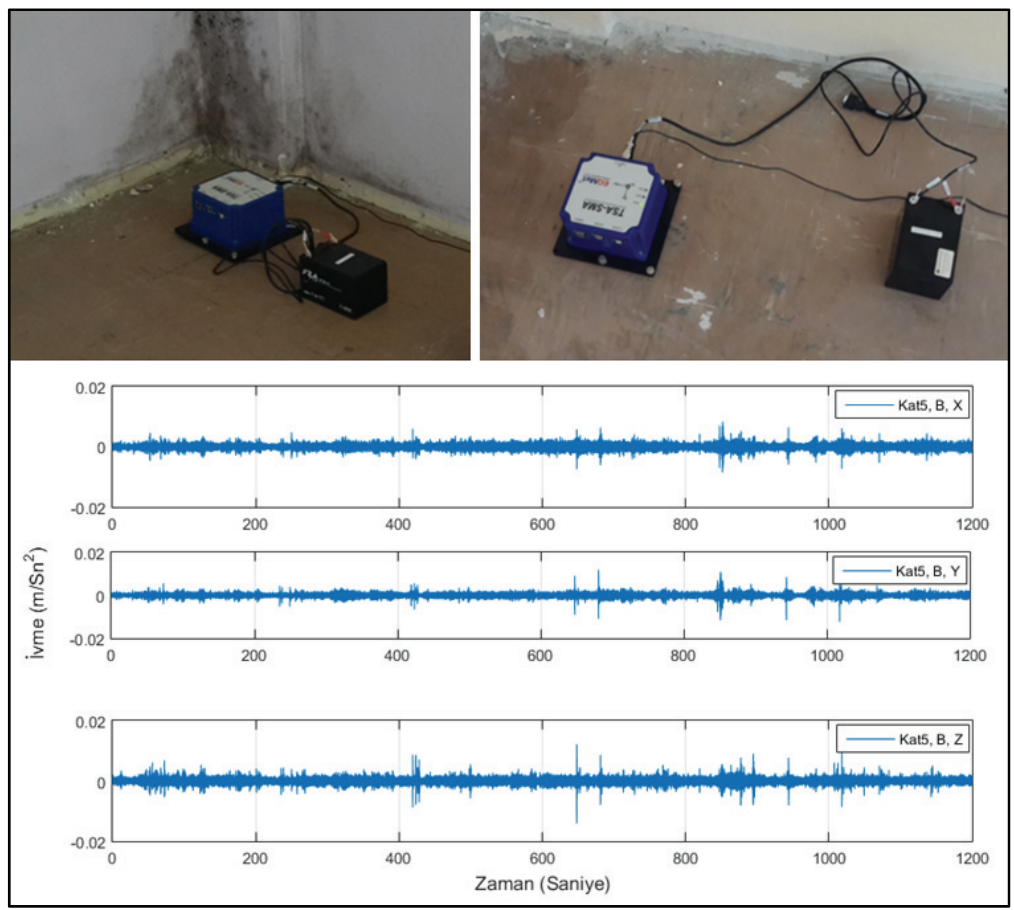

Şekil 4. Binadan titreşim ölçümlerinin alınması ve 5. Kat B köşsesinden alınan ivme ölçümlerinin X, Y ve Z yönündeki değerleri
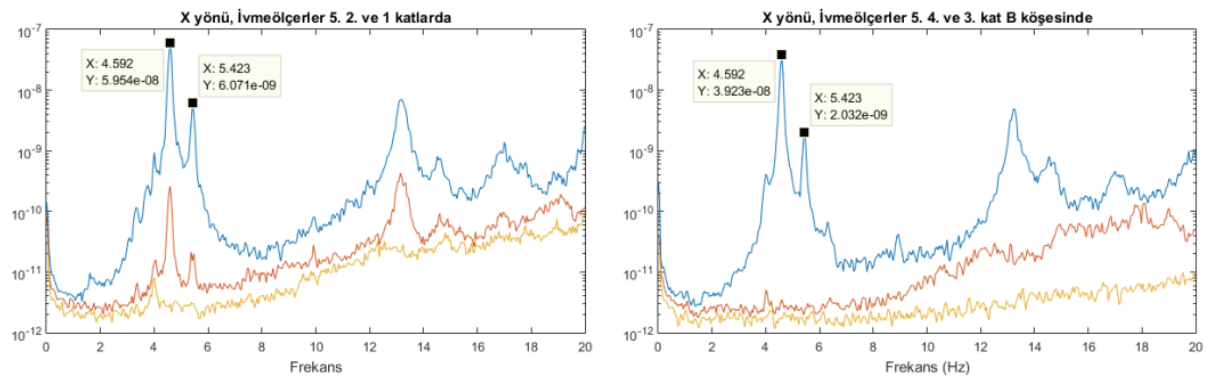

Şekil 5. B köşesi için X yönünde elde edilen CPSD Matris tekil değerleri (iki set ölçüm)
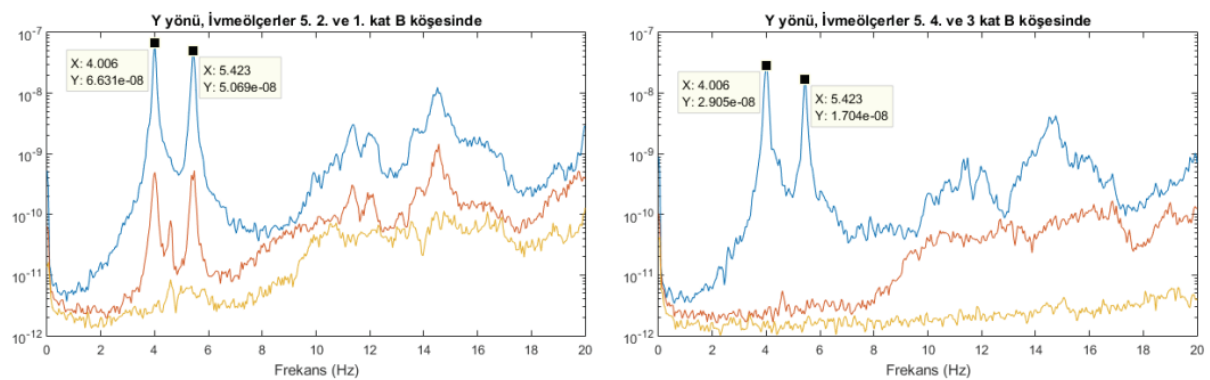

Şekil 6. B köşesi için Y yönünde elde edilen CPSD Matris tekil değerleri (iki set ölçüm) 


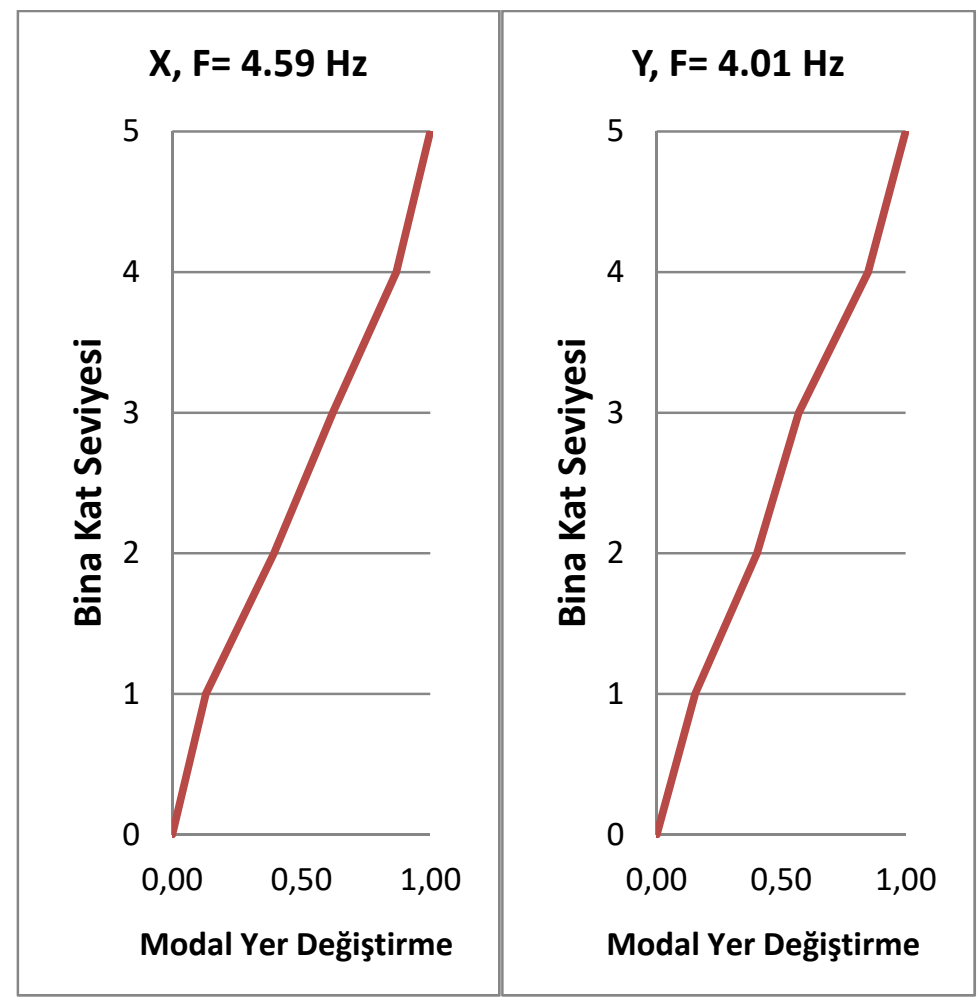

Şekil 7. FOA yöntemi ile elde edilen mod şekilleri

\section{ZEMIN KAT BÖLME DUVARLARIN YIKILMASI}

Çalışmanın genel hedefi betonarme yapılarda duvar etkilerini titreşim analizleri ile incelemek olduğu için binanın duvarsız halinin elde edilmesi gerekmiştir. Bu nedenle zemin kattaki tüm bölme duvarlar, içinde bulundukları çerçevelerden $10-15 \mathrm{~cm}$ aralıkla ayrılmıştır.

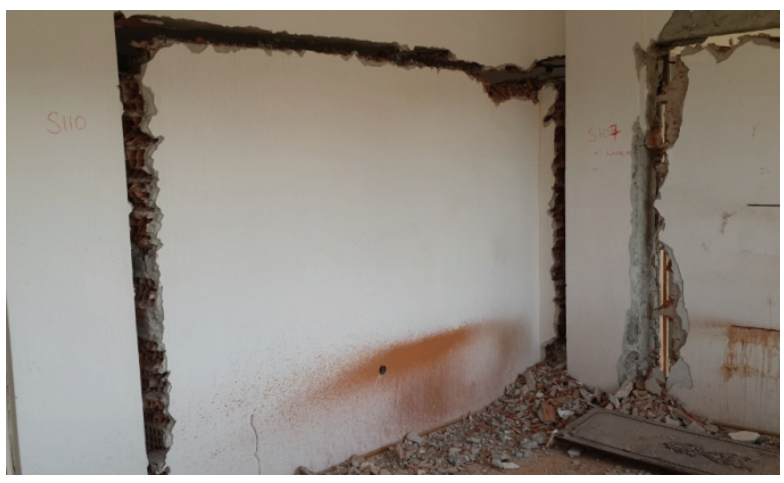

Şekil 8. Duvar ayırma sonrasında yapı içinden görünüş 
Ayırma işlemi darbe etkisi yaratan ve duvarların kırılmasını sağlayan aletlerle yapılmış ve betonarme çerçevenin zarar görmemesine özen gösterilmiştir. Şekil 8 ve Şekil 9 binada gerçekleştirilen duvar - betonarme çerçeve ayırma işlemini göstermektedir. Uygulanan ayırma işleminden sonra duvarlar insan gücüyle bile düzlemleri dışında oynatılabilecek duruma gelmiştir.

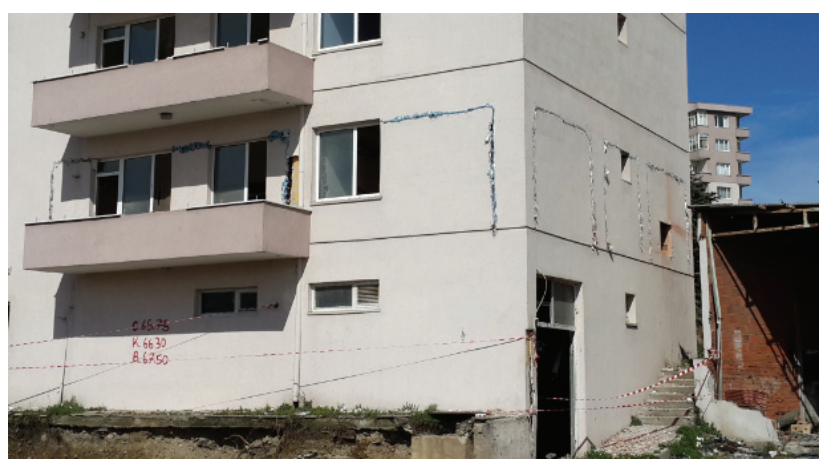

Şekil 9. Duvar ayırma işlemi sonrası yapının dışarıdan görünüşü

\section{ZEMIN KATINDA BÖLME DUVARLARI OLMAYAN BINADA ÇEVRESEL TITREŞIM ANALIZİ}

Bina zemin katında gerçekleştirilen duvar ayırma işleminden sonra binadan titreşim kayıtları alınmıştır (Şekil 10). Kayıtlar ve yöntemle ilgili tüm detaylar, binanın mevcut durumu (zemin kat bölme duvarları yıkılmadan önceki durum) için uygulananlarla aynıdır.

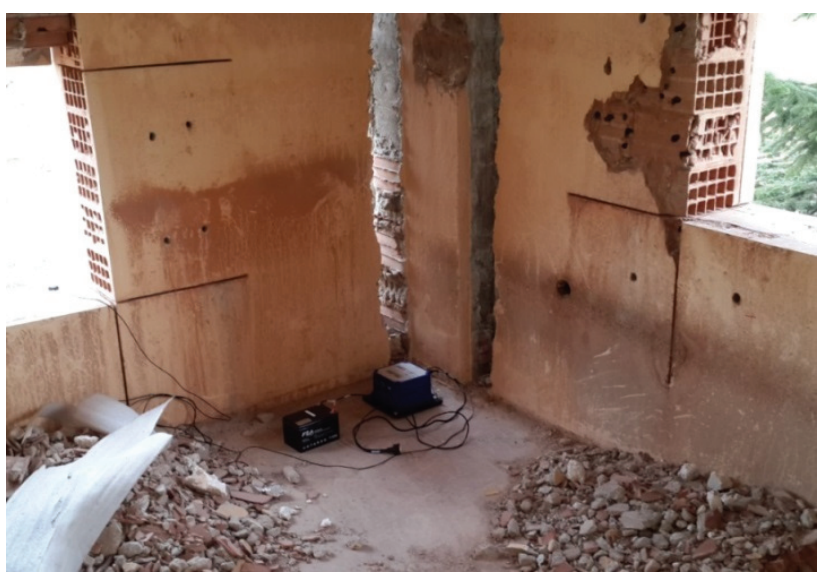

Şekil 10. Zemin katında bölme duvarları etkisizleştirilmiş binadan titreşim kayıtlarının alınması

Binanın zemin katında bulunan duvarların ayrılmasından sonra alınan ivme kayıtları FOA metodu ile değerlendirilmiştir. Şekil 11 ve Şekil 12 binada beşinci kat B köşesi referans 
noktası olarak alındığında ivmeölçerlerin 5. 2. ve 1. katlarda ve 5. 4. ve 3. katlarda olmaları ölçüm setlerinde elde edilen CPSD matrislerinin tekil değerlerini $\mathrm{X}$ ve $\mathrm{Y}$ yönleri için göstermektedirler. Buna göre X yönünde $0-10 \mathrm{~Hz}$ aralığında, 2,93 Hz ve 3,32 Hz frekans değerlerinde iki adet baskın frekans elde edilmiştir. Binanın $\mathrm{Y}$ yönünde ise, $0-10 \mathrm{~Hz}$ aralığında, 3,03 Hz ve 3,32 Hz değerlerinde iki adet baskın frekans elde edilmiştir. Buna göre binanın ilk modu $\mathrm{X}$ yönünde hareket, ikinci modu $\mathrm{Y}$ yönünde hareket, üçüncü modu ise burulma modu olarak tanımlanabilir. Bu yöntemle elde edilen mod şekilleri B köşesi boyunca Şekil 13'te gösterilmiştir. Mod şekillerinin tepe noktası deplasmanı bir olacak şekilde ölçeklendirilmiştir. Binanın 4. ve diğer yüksek modları 10 Hz'in üzerinde tespit edilmiştir.
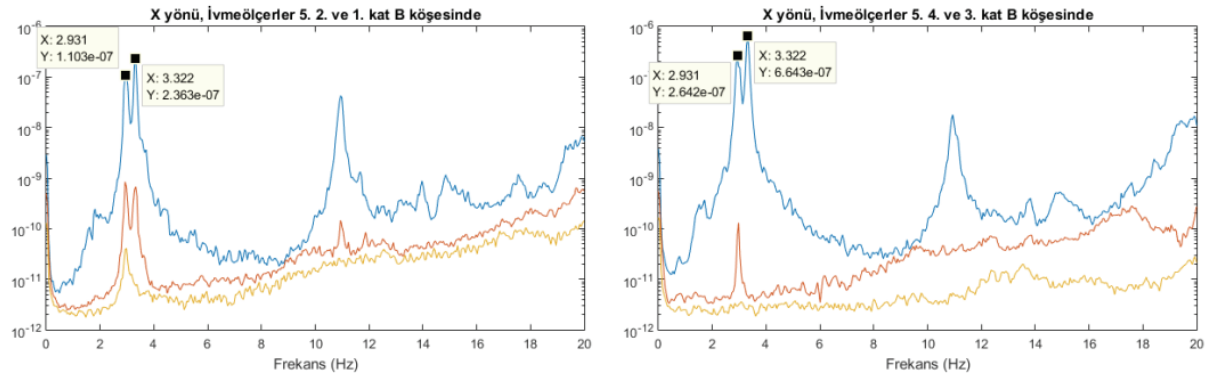

Şekil 11. Zemin katı duvarsız binada B köşesi için Xyönünde elde edilen CPSD matris tekil değerleri (iki set ölçüm)


Şekil 12. Zemin katı duvarsız binada B köşesi için Y yönünde elde edilen CPSD matris tekil değerleri (iki set ölçüm)

\section{DUVARLI VE DUVARSIZ BINANIN DINAMIK ÖZELLIKLERININ KARŞILAŞTIRILMASI}

Betonarme yapılarda kullanılan bölme duvarların, yapıların dinamik özelliklerine olan etkilerini ortaya çıkarmaya yönelik yürütülen bu çalışmada açıklandığı üzere gerçekleştirilen deneyler ve analizler çalışmanın amacına tam olarak ulaşmasını sağlamıştır.

Binanın orijinal ve zemin katında bölme duvarları olmadığ 1 hali için ayrı ayrı gerçekleştirilen dinamik tanımlama sonuçları Şekil 7 ve Şekil 13'ün doğrudan karşılaştırılması ile görülebilir. Buna göre orijinal binanın birinci modu Y yönünde 4,01 Hz, ikinci modu X yönünde 4,59 
$\mathrm{Hz}$, üçüncü modu ise burulma olarak 5,42 Hz'lik frekansla elde edilmiştir. Zemin katında bölme duvarları kaldırılan binada yapılan analizlere göre, binanın birinci mod X yönünde $2,93 \mathrm{~Hz}$, ikinci modu Y yönünde 3,03 Hz, üçüncü modu ise burulma olarak 3,32 Hz'lik frekansla elde edilmiştir. Binanın her iki hali için belirlenmesi mümkün olan yüksek modlar $10 \mathrm{~Hz}$ 'den büyük frekans değerleri ile elde edilmiş ve bina genel davranışını temsil etmemelerinden dolayı değerlendirme dışı bırakılmıştır.

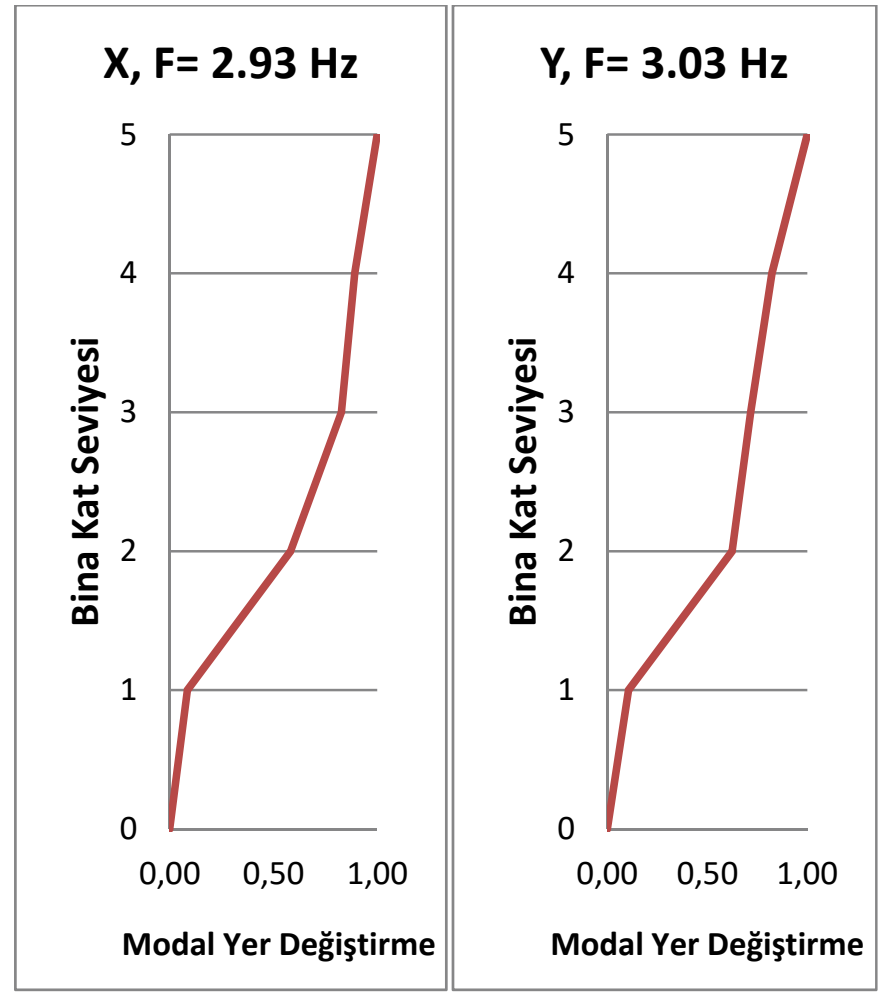

Şekil 13. Zemin katında bölme duvarları olmayan binanın FOA ile elde edilen mod şekilleri

Elde edilen titreşim frekanslarına göre bölme duvarların yapı rijitliğine olan katkısı açıktır. Yürütülen deneysel çalışma sonuçları yapı periyoduna bağlı olarak da değerlendirilebilir. Buna göre yapı zemin katında bulunan bölme duvarların kaldırılması yapının X yönündeki periyodunu 0,218 saniyeden 0,341 saniyeye çıkarmıştır. Ayrıca yine aynı nedenden dolayı yapının Y yönündeki periyodu 0,25 saniyeden 0,33 saniyeye çıkmıştır. Yapının burulma modu periyodu ise 0,184 saniyeden 0,301 saniyeye çıkmıştır.

Yapının zemin katında bulunan bölme duvarların, yapı frekansını etkileme durumlarının daha iyi anlaşılması için bölme duvar kaynaklı frekans artırma oranı, $\Delta_{\mathrm{i}}$, her mod için Denklem 3 ile hesaplanabilir. Bu denklemde $f_{\text {Duvarlı, }}$ zemin katında bölme duvarları olan yapının titreşim frekansını, $f_{\text {Duvarsız }}$ ise zemin katında bölme duvarları olmayan yapının titreşim frekansını göstermektedir. 
$\Delta_{i}=\frac{f_{\text {Duvarll }}-f_{\text {Duvars } I z}}{f_{\text {Duvarsiz }}}$

Elde edilen sonuçlara göre zemin kat bölme duvarları yapının X yönündeki frekansını \% 57 artırmaktayken bu oran Y yönü için \% 32, burulma modu için ise \% 63'tür. Elde edilen bu değerler literatürde karşılaşılan diğer çalışmaların sonuçlarına [3, 7, 11, 12] göre daha yüksektir. Yürütülen çalışmada, ilk önce 30 yaşlarında olan betonarme bir binanın duvarlı halinin test edilmesi, daha sonra binanın zemin katında bulunan bölme duvarların yıkılması ve testlerin tekrarlanması nedeniyle tüm gerçekçi koşulların elde edildiği açıktır. Bu nedenle elde edilen sonuçlar, zamana bağlı malzeme davranışı ve gerçek servis yükleri nedeniyle betonarme çerçeveler ve duvarlar arasındaki bağ ve etkileşimi tam olarak içermektedir. Bölme duvar etkilerinin incelenmesinde önemli olan bu parametrelerin göz önüne alınması belirlenen etkiyi beklendiği üzere daha yüksek göstermektedir.

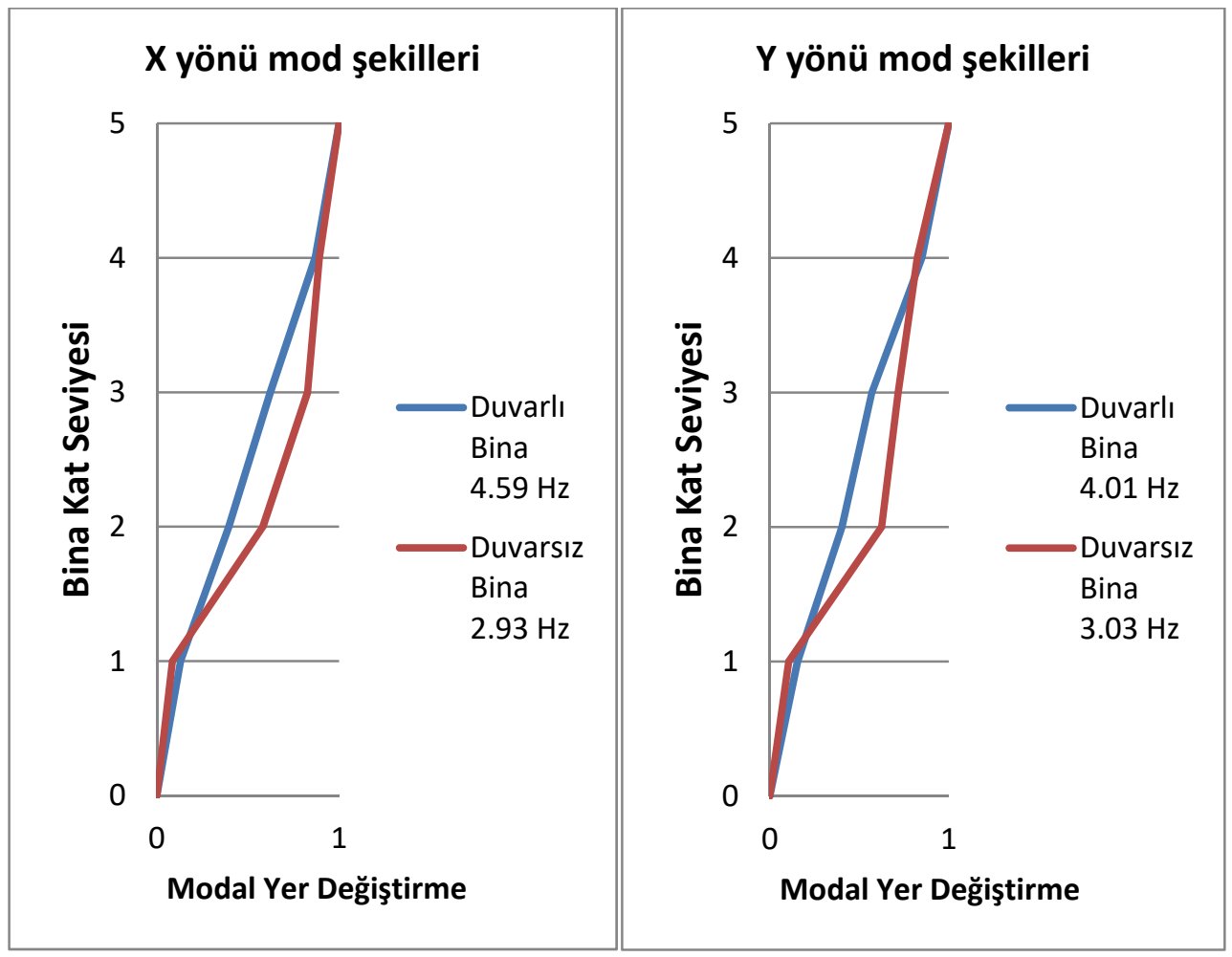

Şekil 14. Binanın iki durumu için elde edilen mod şekilleri

Kat seviyelerinde elde edilen modal yer değiştirmelerin değerlendirilmesi durumunda, orijinal binada bu değerlerin kat seviyesine bağlı olarak düzgüne yakın bir şekilde arttığı görülmektedir. Ancak, zemin katında bölme duvarları kaldırılmış binada modal yer değiştirmelerin birinci ve ikinci kat seviyeleri arasında diğer katlara göre çok fazla arttığ açıkça görülmektedir. Duvar kaldırma işleminin yapıldığı zemin kata denk gelen bu bölümde 
belirlenen yüksek göreli modal yer değiştirme farkı rijitlik azalmasının ve bölme duvarların yapı davranışına olan etkisinin en önemli göstergesidir. Şekil 14 binanın zemin katında bölme duvarların olması ve olmaması durumları için $\mathrm{X}$ ve $\mathrm{Y}$ yönündeki mod şekillerini göstermektedir. Yürürlükteki Türk Deprem Yönetmeliği’nde [18] açıklanan ve yapılmasından kaçınılması önerilen düzensiz bina tanımlamalarından, katlar arası rijitlik düzensizliği (yumuşak kat düzensizliği) durumunun bölme duvarların kaldırılmasından sonra açıkça ortaya çıktığı görülmektedir. Bu durum aşağıdaki bölümde detaylı olarak incelenmiştir.

\section{KOMŞU KATLAR ARASI RİJiTLİK DÜZENSIZLLIĞİNIN İRDELENMESİ}

Türk Deprem Yönetmeliği’nde [18], komşu katlar arası rijitlik düzensizliği, birbirine dik iki deprem doğrultusunun herhangi biri için, herhangi bir i’nci kattaki ortalama kat ötelemesi oranının bir üst veya bir alt kattaki ortalama göreli kat ötelemesi oranına bölünmesiyle elde edilen katsayının $\left(\eta_{\mathrm{ki}}\right)$ 2'den fazla olma durumu olarak tanımlamıştır.

Binanın orijinal ve zemin katının duvarsız hali için elde edilen ve Şekil 14'de gösterilen modal yer değiştirmeler, komşu katlar arası rijitlik düzensizliği kontrolü için kullanılabilir. Özellikle düzenli taşıyıcı sisteme ve dikdörtgen geometriye sahip binalarda deprem kuvvetleri altında oluşan göreli yanal ötelenmeler, binanın dinamik mod şekillerine yakın hesaplanır. Bu kabulle, Tablo 1 mevcut duvarlı binanın, Tablo 2 ise zemin katında duvar bulunmayan binanın yumuşak kat düzensizliği kontrolünü göstermektedir. Tablolarda $\mathrm{h}_{\mathrm{i}}$ : kat yüksekliğini, $\phi_{\mathrm{i}}$ : kat modal yer değiştirmesini, $\Delta \phi_{\mathrm{i}}$ : kat göreli modal yer değiştirmesini ve $\eta_{\mathrm{ki}}$ : kat rijitlik düzensizliği katsayısını göstermektedir. Düzenlenen tabloda $\eta_{k i}$ üst kat göreli modal yer değiştirme oranının alt kat göreli modal yer değiştirme oranına oranı olarak hesaplanmıştır. Bu nedenle Rijitlik Düzensizliği Katsayısının 2'den büyük ve 0,5'den küçük olma halleri komşu katlar arasında rijitlik düzensizliğinin varlığına işaret etmektedir.

Elde edilen deneysel sonuçlara göre duvarlı binada zemin ve bodrum kat göreli modal yer değiştirmelere göre hesaplanan Rijitlik Düzensizliği Katsayısı X ve Y yönlerinde 2 değerini aşarak yumuşak kat düzensizliğinin varlığına işaret etmiştir. Hesaplanan Rijitlik Düzensizliği Katsayısı 2,72 ve 2,17'dir. Diğer katlar arasında rijitlik düzensizliği bulunmamaktadır.

Tablo 1. Duvarlı binada komşu katlar arası rijitlik düzensizliğinin kontrolü

\begin{tabular}{|c|c|c|c|c|c|c|c|c|c|}
\hline \multirow{2}{*}{ Kat } & \multirow{2}{*}{$\mathrm{h}_{\mathrm{i}}$} & \multicolumn{3}{|c|}{ Duvarl1 Bina - X Yönü } & \multicolumn{4}{c|}{ Duvarlı Bina - Y Yönü } \\
\cline { 3 - 10 } & & $\phi_{\mathrm{i}}$ & $\Delta \phi_{\mathrm{i}}$ & $\Delta \phi_{\mathrm{i}} / \mathrm{h}_{\mathrm{i}}$ & $\eta_{\mathrm{ki}}$ & $\phi_{\mathrm{i}}$ & $\Delta \phi_{\mathrm{i}}$ & $\Delta \phi_{\mathrm{i}} / \mathrm{h}_{\mathrm{i}}$ & $\eta_{\mathrm{ki}}$ \\
\hline 5 & 2.9 & 1.000 & 0.132 & 0.045 & 0.535 & 1.000 & 0.151 & 0.052 & 0.541 \\
\hline 4 & 2.9 & 0.868 & 0.246 & 0.085 & 1.080 & 0.849 & 0.279 & 0.096 & 1.664 \\
\hline 3 & 2.9 & 0.622 & 0.228 & 0.079 & 0.863 & 0.570 & 0.168 & 0.058 & 0.675 \\
\hline 2 & 2.9 & 0.394 & 0.264 & 0.091 & 2.722 & 0.403 & 0.248 & 0.086 & 2.162 \\
\hline 1 & 3.9 & 0.130 & 0.130 & 0.033 & & 0.154 & 0.154 & 0.040 & \\
\hline
\end{tabular}


Tablo 2. Zemin katta duvar bulunmayan binada komşu katlar arası rijitlik düzensizliğinin kontrolü

\begin{tabular}{|c|c|c|c|c|c|c|c|c|c|}
\hline \multirow[b]{2}{*}{ Kat } & \multirow[b]{2}{*}{$\mathrm{h}_{\mathrm{i}}$} & \multicolumn{4}{|c|}{ Duvarsız Bina - X Yönü } & \multicolumn{4}{|c|}{ Duvarsız Bina - Y Yönü } \\
\hline & & $\phi_{\mathrm{i}}$ & $\Delta \phi_{\mathrm{i}}$ & $\Delta \phi_{\mathrm{i}} / \mathrm{h}_{\mathrm{i}}$ & $\eta_{\mathrm{ki}}$ & $\phi_{\mathrm{i}}$ & $\Delta \phi_{\mathrm{i}}$ & $\Delta \phi_{\mathrm{i}} / \mathrm{h}_{\mathrm{i}}$ & $\eta_{\mathrm{ki}}$ \\
\hline 5 & 2.9 & 1.000 & 0.109 & 0.038 & 1.698 & 1.000 & 0.177 & 0.061 & 1.664 \\
\hline 4 & 2.9 & 0.891 & 0.064 & 0.022 & 0.262 & 0.823 & 0.106 & 0.037 & 1.145 \\
\hline 3 & 2.9 & 0.827 & 0.245 & 0.084 & 0.493 & 0.717 & 0.093 & 0.032 & 0.179 \\
\hline 2 & 2.9 & 0.582 & 0.497 & 0.171 & 7.823 & 0.624 & 0.519 & 0.179 & 6.600 \\
\hline 1 & 3.9 & 0.085 & 0.085 & 0.022 & & 0.106 & 0.106 & 0.027 & \\
\hline
\end{tabular}

Zemin katta bölme duvar bulunmayan binada zemin kat ve bodrum kat için hesaplanan Rijitlik Düzensizliği Katsayıları, X ve Y yönünde 7,82 ve 6,6 olarak hesaplanmıştır. Bu nedenle bölme duvarların komşu katlar arasında rijitlik düzensizliği kontrolünde dikkate alınması gerekliliği açıktır. Elde sonuçlar özellikle zemin katlarının ticari alanlar olarak kullanılması için bölme duvarsız olarak inşa edilen binalardaki düzensizlik durumlarının ortaya çıkarılması için önemlidir. Bina tasarımlarında kullanılan sayısal modeller genel olarak bölme duvarları ihtiva etmediğinden bu düzensizliğin kontrol edilmesinde de bölme duvarlar göz önüne alınmamaktadır. Bu durum önemli bir eksiklik olarak görülmektedir.

\section{SONUÇLAR}

Bölme duvarların betonarme yapıların dinamik özelliklerine olan etkisini ortaya çıkarmak için mevcut bir binanın deney numunesi olarak kullanılmasıyla yürütülen bu çalışmada önemli bulgular elde edilmiştir. Binanın mevcut halinin dinamik özellikleri çevresel titreşim analizleriyle elde edildikten sonra zemin katında bulunan bölme duvarları etkisizleştirilmiş ve dinamik özellikleri tekrar elde edilmiştir. Bu nedenle elde edilen sonuçlar hiçbir varsayım ve kabule dayanmadan kesindir. Çalışmada elde edilen sonuçlar aşağıdaki gibi özetlenebilir;

Mevcut binanın birinci modu Y yönünde 4,01 Hz, ikinci modu X yönünde 4,59 Hz, üçüncü modu ise burulma olarak 5,42 Hz'lik frekansla elde edilmiştir. Aynı binanın zemin katında bölme duvarları kaldırıldıktan sonra, binanın birinci modu X yönünde $2,93 \mathrm{~Hz}$, ikinci modu Y yönünde 3,03 Hz, üçüncü modu ise burulma olarak 3,32 Hz'lik frekansla elde edilmiştir.

Buna göre bölme duvarlar yapının rijitliğine önemli katkılar yapmaktadır. Buna göre, zemin katta bölme duvarların varlığı yapının X yönündeki frekansını 2,93 Hz'den 4,59 Hz'e çıkarmıştır ve bu fark \%57'lik bir yükseliş ifade etmektedir. Aynı şekilde, zemin katta bölme duvarların varlığı yapının Y yönündeki frekansını 3,03 Hz'den 4,01 Hz'e çıkarmıştır ve bu fark \% 32'lik bir yükselişe denk gelmektedir. Burulma modu için elde edilen frekans yükselişi \% 63 'tür. 
Literatürde yürütülen diğer çalışmalara göre daha yüksek olarak elde edilen etki, yürütülen çalışmanın, gerçek bir binada yürütülen ve zamana bağlı malzeme davranışını tam içeren bir çalışma olması nedeniyle, özgünlüğü açısından önemlidir.

Binanın zemin katında bölme duvarların olması ve olmaması için elde edilen mod şekillerinin karşılaştırılması, bölme duvarların Türk Deprem Yönetmeliği’nde (2007) tanımlanan yumuşak kat düzensizliğinin kontrol edilmesinde oldukça etkili olduklarını göstermiştir. Özellikle zemin katlarının ticari amaçlarla kullanıldığ 1 ve bu nedenle bölme duvarların olmadığı binalarda, yumuşak kat düzensizliğinin kontrolünde bölme duvar etkilerinin göz önüne alınmamasının hatalara neden olacağı açıktır.

\section{Semboller}

$\mathrm{f}_{\text {Duvarlı }} \quad$ : Zemin katı duvarlı binanın titreşim frekansı

$\mathrm{f}_{\text {Duvarsız }} \quad$ : Zemin katı duvarsız binanın titreşim frekansı

$\left[G_{x x}(w)\right]$ : Etki sinyallerine ait güç spektral yoğunluk fonksiyonları

$\left[G_{y y}(w)\right]:$ Tepki sinyallerine ait güç spektral yoğunluk fonksiyonları

$[H(w)] \quad$ :Frekans davranış fonksiyonu

$\mathrm{h}_{\mathrm{i}} \quad$ : Kat yüksekliği

$\mathrm{U}_{\mathrm{i}} \quad$ : Tekil mod vektörlerinden oluşan birim matrisi,

$\mathrm{u}_{\mathrm{ij}} \quad$ : Tekil mod vektörleri

$\mathrm{S}_{\mathrm{i}} \quad$ : Tekil öz değerlerden oluşan diyagonal matrisi

$\mathrm{s}_{\mathrm{ij}} \quad$ : Tekil öz değerler

T : : Transpoze operasyonu

: Eşlenik operasyonu

$\Delta_{\mathrm{i}} \quad$ : Zemin kat duvarlarının neden olduğu modal frekans artışı

$\Delta \phi_{\mathrm{i}} \quad$ : Katlar arası göreli modal yer değiştirme

$\phi_{\mathrm{i}} \quad$ : Modal yerdeğiştirme

$\eta_{\mathrm{ki}} \quad$ : Rijitlik düzensizliği katsayısı

\section{Teşekkür}

Bu çalışma TÜBITAK, Kariyer Geliştirme Programı kapsamında yürütülen 214M235 numaralı proje içerisinde gerçekleştirilmiştir. Ayrıca analizler için verilen destekten ötürü yazar, University of Alberta'dan, Dr. Mustafa Gül'e teşekkürü borç bilir. 


\section{Kaynaklar}

[1] Fiore, A., Netti, A., Monaco, P., The influence of masonry infill on the seismic behaviour of RC frame buildings, Engineering Structures, 44, 133-145, 2012.

[2] Uva, G., Porco, F., Fiore, A., Appraisal of masonry infill walls effect in the seismic response of RC framed buildings: A case study, Engineering Structures 34, 514-526, 2012.

[3] Köse, M. M. Parameters affecting the fundamental period of RC buildings with infill walls, Engineering Structures, 31, 93-102, 2009.

[4] Mehrabi, A. B., Shing, P. B., Schuller, M. P., Noland, L., Experimental Evaluation of Masonry-Infilled RC Frames, J. Struct. Eng, 122(3), 228-237, 1996.

[5] Zarnic, R., Gostic, S., Crewe, A. J., and Taylor, C. A., Shaking table tests of 1:4 reduced-scale models of masonry infilled reinforcedconcrete frame buildings, Earthquake Eng. Struct. Dyn., 30(6), 819-834, 2001.

[6] Hashemi, A., and Mosalam, K. M., Shake-table experiment on reinforced concrete structure containing masonry infill Wall, Earthquake Eng. Struct. Dyn., 35(14), 1827$1852,2006$.

[7] Çankaya, M. A., Dynamic Behavior of Reinforced Concrete Frames with Infill Walls, MASTER Thesis, İzmir Institute of Technology, İzmir, 2011.

[8] Bayraktar, A., Türker, T., Altunışık, A. C., Sevim, B., Şahin, A., Özcan, D. M., Binaların Dinamik Parametrelerinin Operasyonal Modal Analiz Yöntemiyle Belirlenmesi. İMO Teknik Dergi, 5185-205, 2010.

[9] Ewins, D. J., Modal Testing: Theory and Practice. John Wiley \& Sons, New York, 1995.

[10] Michel, C., Gueguen, P., and Bard, P.-Y., Dynamic parameters of structures extracted from ambient vibration measurements: An aid for the seismic vulnerability assessment of existing buildings in moderate seismic hazard regions, Soil Dynamics and Earthquake Engineering, 28, 593-604, 2008.

[11] Guler, K., Yuksel, E., and Kocak, A., Estimation of the fundamental vibration period of existing RC buildings in Turkey utilizing ambient vibration records. J. Earthquake Eng., 12(S2), 140-150, 2008.

[12] Soyoz, S., Taciroglu, E., Orakcal, K., Nigbor, R., Skolnik, D., Lus, H., Safak, E., Ambient and Forced Vibration Testing of a Reinforced Concrete Building before and after Its Seismic Retrofitting. J. Struct. Eng. 139:1741-1752, 2013.

[13] ABYYHY, Afet Bölgelerinde yapılacak yapılar hakkında yönetmelik, T.C. İmar ve İskan Bakanlığg, Deprem Araştırma Enstitüsü Başkanlığı, Ankara, 1975.

[14] Aras F., Frequency variation in construction stages and model validation for steel buildings, Steel and Composite Structures, 22, 647-662, 2016.

[15] Aras F., Ambient and forced vibration testing with numerical identification for RC buildings, Earthquakes and Structures, 11, 809-822, 2016. 
[16] Brincker, R., Ventura, C., and Andersen, P., "Why ouput-only modal testing is a desirable tool for a wide range of practical applications" In 21st international modal analysis conference (IMAC), Kissimmee, Florida, 2003.

[17] Matlab, The MathWorks, Inc., Natick, Massachusetts, United States, 2012.

[18] DBYBHY, Deprem Bölgelerinde Yapılacak Binalar Hakkında Esaslar. Bayındırlık ve İskan Bakanlığı, Türkiye, 2007. 
